\title{
Surgical Treatment of Fracture-Dislocation of the Femoral Head Pipkin IV: About One Case and Literature Review -Case Report
}

Seddik Benchekroun*, Senhaji Said, Lahsika Mohammed, Maanouk Rachid, Abid Hatim, El Idrissi Mohamed, El Ibrahimi Abdelhalim, El Mrini Abdelmaji

Department of Orthopedic, University Hospital Center HASSAN II fez, 30000 fez, Morocco

DOI: $\underline{10.36347 / \text { sasjs.2020.v06i06.002 }}$

| Received: 06.06.2020 | Accepted: 13.06.2020 | Published: 16.06.2020

*Corresponding author: Seddik Benchekroun

Abstract

The fracture of the Pipkin femoral head type IV is a rare pathological entity whose treatment is surgical already represented a poor prognosis. That said there are several surgical approaches to treat this delicate pathology. In the literature, the opinions of the authors diverge concerning the choice of the approach initially, but the conservation of the cephalic fragment is the rule. Regardless of the quality of care, poor and fair results are very important, estimated at $50 \%$ after 10 years, and long-term arthritis development seems to be inevitable.

Keywords: Pipkin, poor prognosis, pathology.

Copyright @ 2020: This is an open-access article distributed under the terms of the Creative Commons Attribution license which permits unrestricted use, distribution, and reproduction in any medium for non-commercial use (NonCommercial, or CC-BY-NC) provided the original author and source are credited.

\section{INTRODUCTION}

The incidence of parcel fractures of the femoral head occurring during hip dislocation is 8 to $26 \%$.

These lesions are rare and the irreducible varieties are even more, so the latter seriously compromise the future functional prognosis of the hip by a $20 \%$ risk of osteonecrosis and osteoarthritis at 5 years.

The treatment of dislocations with fragmentary fractures of the femoral head is difficult, as much for the choice of the approach first as for the attitude towards the fractured fragment. In this work, we report the case of an irreducible luxation-fracture of the Pipkin IV femoral head.

\section{CASE PRESENTATION}

A 32-year-old patient, with no notable pathological history, admitted to the emergency department for closed trauma to the hip left three hours from a public road accident.

The clinical examination on admission found a patient who was conscious and stable on the hemodynamic and respiratory levels with, on locomotor examination, a vicious attitude of the right lower limb in flexion of the hip adduction internal rotation without vasculo-nervous deficit distally.
Standard radiography allowed the diagnosis of a posterior luxation fracture Pipkin IV of the left hip, the head being indented on the posterior wall of the acetabulum (Figure-1).

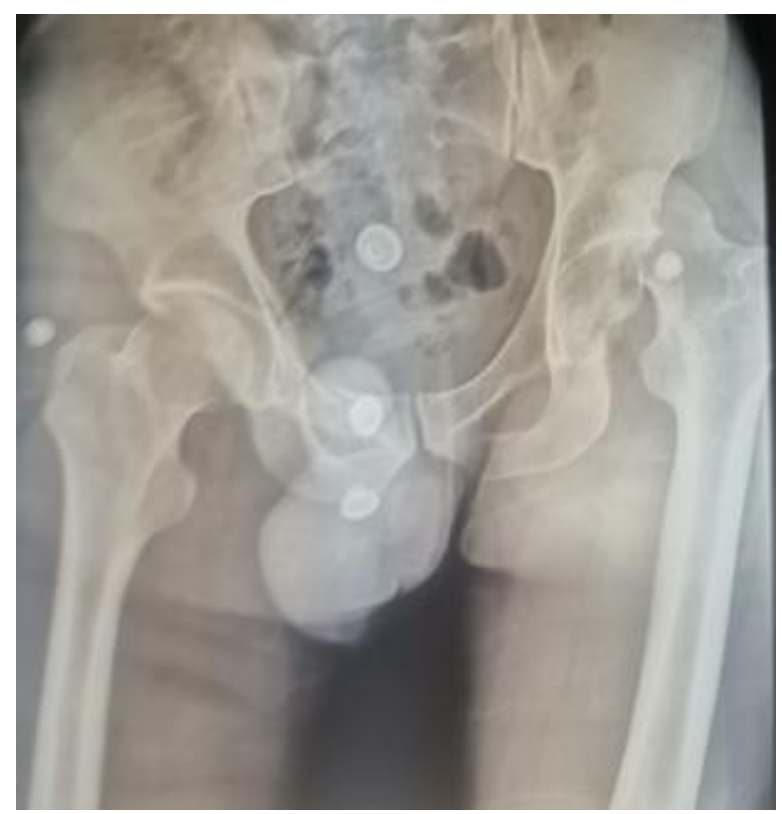

Fig-1: X-ray of the pelvis showing a Pipkin IV fracture of the femoral head 
An attempt at reduction under general anesthesia was carried out 4 hours after the trauma, with success.
Therefore, after a satisfactory reduction, we completed with a scanner to better analyze the lesions confirming that it is a fracture of the Pipkin IV femoral head (Figure $2 \& 3$ ).

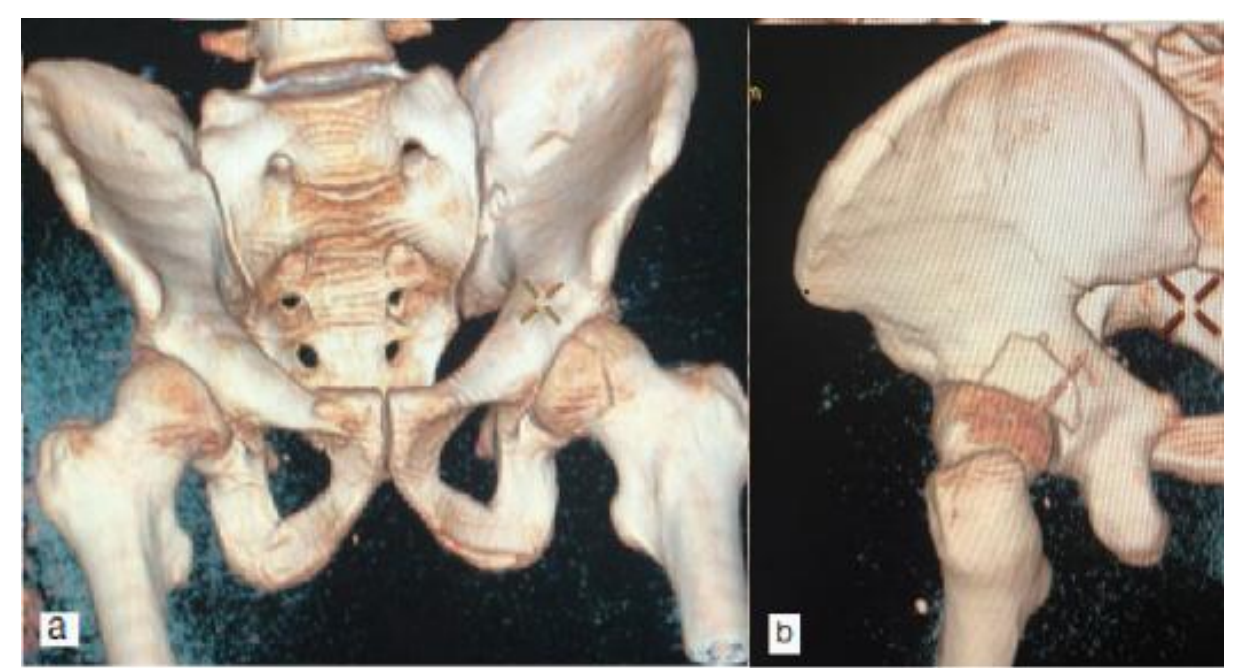

Fig-2: CT image with 3D reconstruction - a: fragment of head - b: the posterior wall of the acetabulum

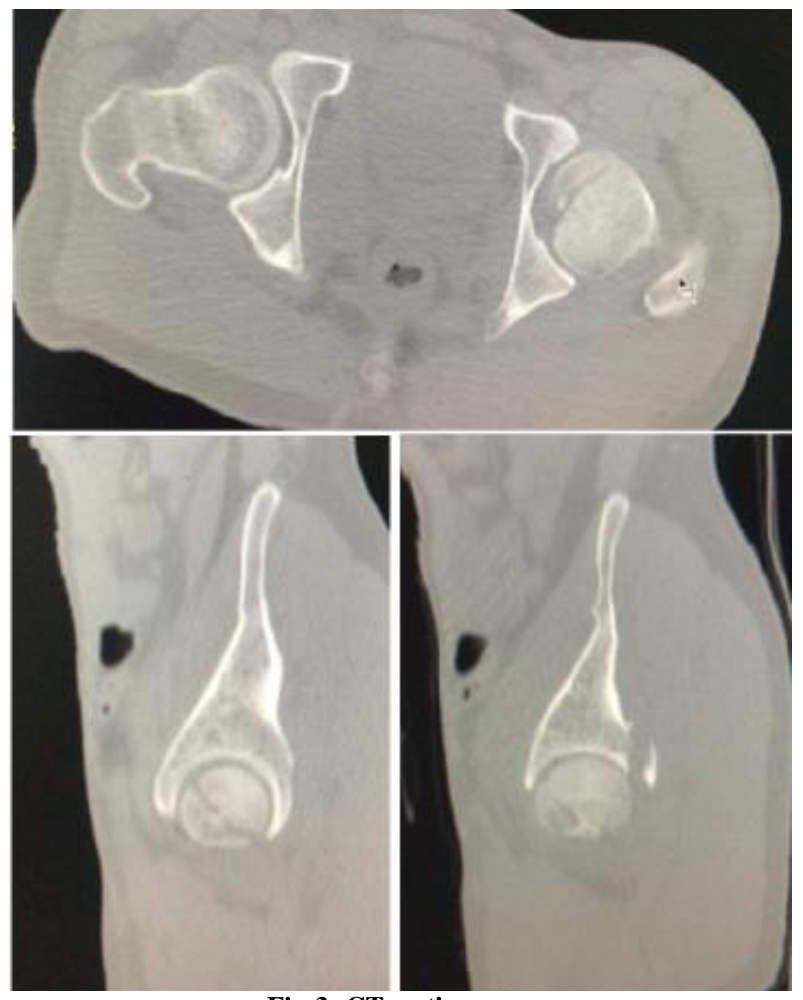

Fig-3: CT sections

The next day we opted for a surgical treatment, we approached the articulation by first approach of Kocher-langenbeck: the exploration had objectified a partial section of the pelvic-trochanteric muscles, We proceeded by a dislocation of the femoral head objectifying a fragment which presented $1 / 3$ of the size of the head, in addition the approach allowed us to reach the post wall of the acetabulum (Figure-4). 


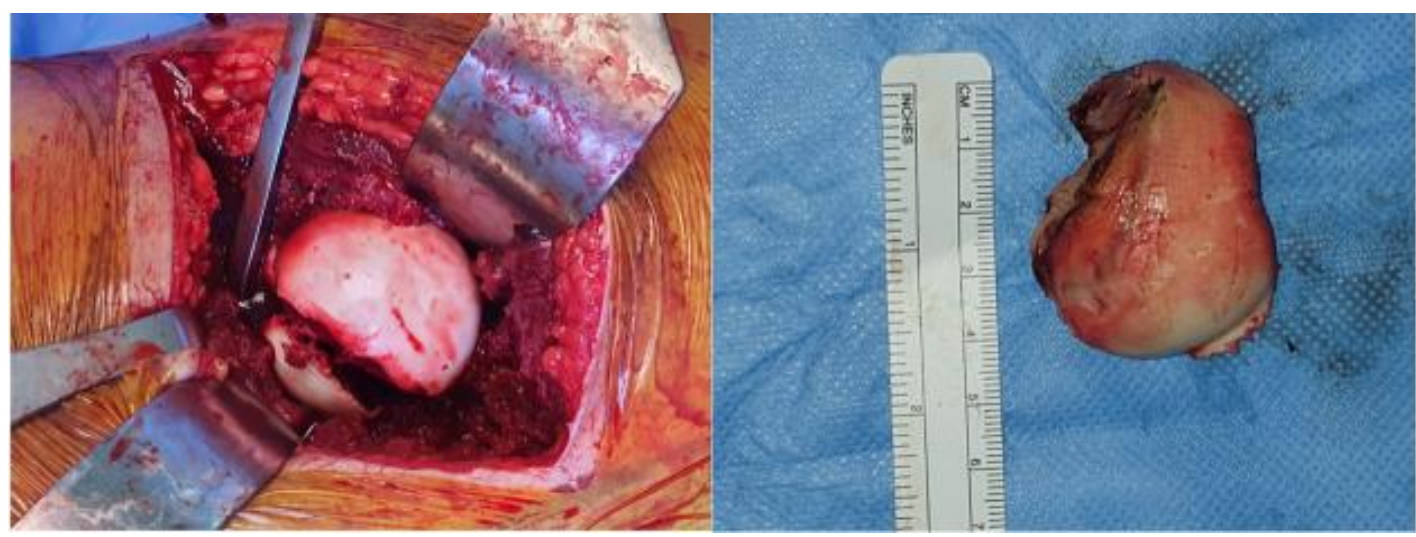

Fig-4: Intraoperative View

We then continued by reducing the fragment of the femoral head and osteosynthesis by 3 screw of herbert thus an osteosynthesis of the post wall of the acetabulum by two cortical screws 4,5 (Figure-5).

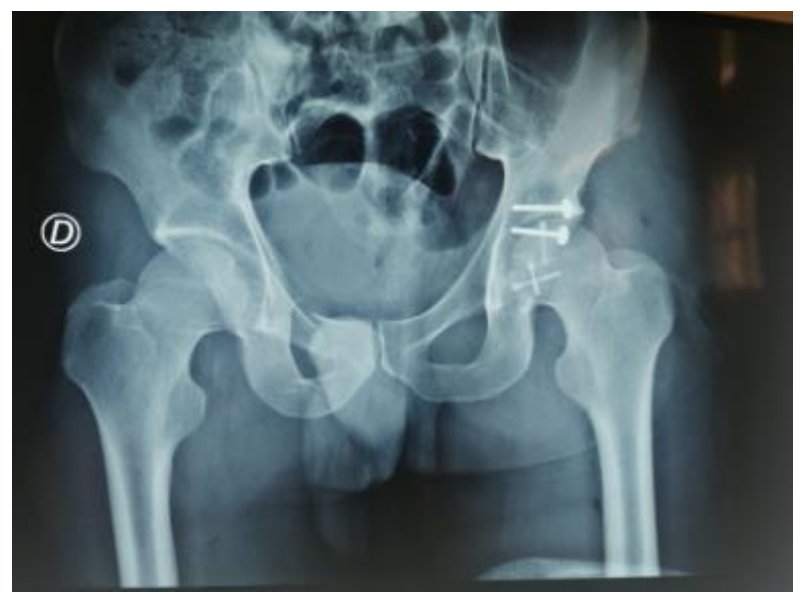

Fig-5: Post-operative pelvis x-ray

After 12 months, the functional result is considered excellent according to the Postel Merle d'Aubigné score (PMA at 16 points), this without radiological anomalies.

\section{DISCUSSION}

The pipkin classification system remains the most widely used means of fracturing the femoral head [1], This classification often makes reference because it is the first to present a prognostic and therapeutic interest. However, it does not include osteochondral fragments, compaction fractures; it also does not differentiate between fractures $1 / 4,1 / 3$ or $1 / 2$ of the head. In addition, groups III and IV no longer specify the size of the fragment. Fractured femoral head is a rare injury, which usually occurs after traumatic posterior dislocation of the hip joint. According to statistics, approximately $5 \%$ e $15 \%$ of the posterior hip dislocations were associated with femoral broken head $[2,3]$.

We can say that the traumatic posterior dislocation of the hip is the result of a force applied axially on the femoral diaphysis flexion, adduction and internal rotation of the hip.

The most common injury to the dashboard is a passenger's knee hitting the dashboard in a collision with a motor vehicle. $[4,5]$ position of the leg at the time of the accident determines whether the hip becomes dislocated with or without additional bone lesions on the femoral head or posterior wall of the acetabulum.

Surgery remains an effective treatment for fracture of the Pipkin IV femoral head, which can restore the anatomical structure of the hip joint, early functional training, and promote recovery from postoperative function. Treatment principles include reduction of associated hip dislocation, early anatomical reduction, rigid fixation of large fragments, restoration of hip congruence and stability and removal of small and crushed intra-articular fragments [6].

The Optimal Surgical Approach for Treatment of the Pipkin Type Fractures of the IV femoral head remain controversial. Several approaches have been recommended, The posterior approach can provide good exposure of the acetabular fracture and an opportunity for simultaneous repair of the femoral head and acetabular fractures.

At the same time, surgery should be performed carefully to reduce stripping and cutting of the gluteal muscles as much as possible, in order to protect the remaining blood supply from the hip joint and reduce the incidence of postoperative avascular necrosis of the femoral head 25 [7].

Previous studies have recommended excision of all fragments, provided that the fragments make up less than a third of the femoral head [2].

Furthermore, in the treatment of acetabular posterior wall fractures, anatomical reduction is particularly important. The quality of the reduction is directly linked to postoperative joint function $[8,9]$ 
Gansslen et al., [10] thought that the largest fragment could be fixed with hollow screws, and that when the fracture involves the posterior column, the fixation of the fracture must be carried out with a reconstruction plate

\section{Complications}

- Post-traumatic osteoarthritis is the most common complication of a fracture of the femoral head, and its incidence is directly related to the quality of fracture reduction $[11$, $12]$.

- The incidence of traumatic lesions of the sciatic nerve range from $7.0 \%$ to $27.0 \%$ [13, 14].

- Avascular necrosis of the femoral head has been identified as post-traumatic complications from femoral head fractures and can lead to hip function restrictions and permanent disability.

In this study, we adopted the posterior KocherLangenbeck which prevents further destruction of the soft tissue of the anterior hip and preserves the blood supply to the anterior capsule; however, surgery should be performed with care to reduce stripping and cutting of the gluteal muscles to protect the remaining blood supply from the hip joint and reduce the incidence of postoperative avascular necrosis of the femoral head.

\section{CONCLUSION}

In conclusion, Due to the complexity of the anatomical structure, surgical treatment is particularly difficult and more likely to result in development of post-traumatic osteoarthritis, avascular necrosis of the femoral head and other complications. In order to remediate these complications for the treatment of Fractures of the Pipkin femoral head type IV, it is preferable to obtain a rapid reduction of the dislocation of the hip, with a good surgical approach in particular an anatomical reduction and solid internal fixation of the fracture and restoration of hip congruence and stability.

\section{REFERENCES}

1. Giannoudis PV, Kontakis G, Christoforakis Z, Akula M, Tosounidis T, Koutras C. Management, complications and clinical results of femoral head fractures. Injury. 2009 Dec 1;40(12):1245-51.
2. Epstein HC, Wiss DA, Cozen LE. Posterior fracture dislocation of the hip with fractures of the femoral head. Clinical orthopaedics and related research. $1985 \operatorname{Dec}(201): 9-17$.

3. Mostafa MF, El-Adl W, El-Sayed MA. Operative treatment of displaced Pipkin type I and II femoral head fractures. Archives of orthopaedic and trauma surgery. 2014 May 1;134(5):637-44.

4. Davis JB. Simultaneous femoral head fracture and traumatic hip dislocation. The American Journal of Surgery. 1950 Dec 1;80(7):893-5.

5. FUNSTEN RV, Kinser P, FRANKEL CJ. Dashboard dislocation of the hip: a report of twenty cases of traumatic dislocation. Jbjs. 1938 Jan 1;20(1):124-32.

6. Droll KP, Broekhuyse H, O'Brien P. Fracture of the femoral head. JAAOS-Journal of the American Academy of Orthopaedic Surgeons. 2007 Dec 1;15(12):716-27.

7. Stannard JP, Harris HW, Volgas DA, Alonso JE. Functional outcome of patients with femoral head fractures associated with hip dislocations. Clinical Orthopaedics and Related Research®. 2000 Aug 1;377:44-56.

8. Alexa O, Malancea RI, Puha B, Luncã S, Veliceasa B. Results of Surgical Treatment of Acetabular Fractures Using Kocher-Langenbeck Approach. 7.

9. Mears DC, Velyvis JH, Chang CP. Displaced acetabular fractures managed operatively: indicators of outcome. Clinical Orthopaedics and Related Research®. 2003 Feb 1;407:173-86.

10. Gänsslen A, Steinke B, Krettek C. Osteosynthese von Frakturen der hinteren Wand des Azetabulums. Oper Orthop Traumatol. 2009 Sep 1;21(3):283- 95

11. Judet R, Judet J, Letournel E. Fractures of the acetabulum: classification and surgical approaches for open reduction: preliminary report. JBJS. 1964 Dec 1;46(8):1615-75.

12. Negrin LL, Seligson D. Results of 167 consecutive cases of acetabular fractures using the KocherLangenbeck approach: a case series. Journal of orthopaedic surgery and research. 2017 Dec 1;12(1):66.

13. Henle P, Kloen P, Siebenrock KA. Femoral head injuries: which treatment strategy can be recommended?. Injury. 2007 Apr 1;38(4):478-88.

14. Ross JR, Gardner MJ. Femoral head fractures. Current reviews in musculoskeletal medicine. 2012 Sep 1;5(3):199-205. 